\title{
Abiraterone/Prednisone Regimen
}

National Cancer Institute

\section{Source}

National Cancer Institute. Abiraterone/Prednisone Regimen. NCI Thesaurus. Code

C160503.

A regimen consisting of abiraterone and prednisone that can be used for the treatment of prostate cancer. 